\title{
Short-term perturbation in aerosol characteristics over Northwestern India: A case study during Diwali festival
}

\author{
Onam Bansal*®, Atinderpal Singh and Darshan Singh \\ Department of Physics, Punjabi University, Patiala 147 002, India. \\ *Corresponding author.e-mail: onubansal@gmail.com
}

MS received 27 August 2018; revised 2 May 2019; accepted 7 May 2019; published online 5 July 2019

The present study examines the effect of Diwali festival (17-21 October 2017; 19th October was the Diwali day) on aerosol characteristics over Patiala, northwestern part of India. Diwali being one of the major festivals of India that falls between mid-October and mid-November is celebrated with full enthusiasm by burning crackers, fireworks, etc. During this period, the study site also is engulfed with high aerosol loading because of extensive paddy residue burning emission. During Diwali event, a particulate matter $\left(\mathrm{PM}_{10}\right)$ concentration varies from 132 to $155 \mu \mathrm{g} \mathrm{m}{ }^{-3}$, while a mass concentration of black carbon aerosols varies from 6 to $9 \mu \mathrm{g} \mathrm{m}{ }^{-3}$ with the maximum concentration on post-Diwali day. Aerosol optical depth $\left(\mathrm{AOD}_{500}\right)$ was maximum $(0.852)$ on post-Diwali day indicating the additional loading of submicron particles due to burning of crackers and fireworks. The magnitude of single scattering albedo $\left(\mathrm{SSA}_{500}\right)$ decreases to a minimum value around 0.864 showing abundance of absorbing aerosols on Diwali affected days (19th and 20th October). A sudden jump of $+12.9 \mathrm{~W} \mathrm{~m}^{-2}$ in atmospheric radiative forcing resulting in a heating rate of up to $1.4 \mathrm{~K} \mathrm{day}^{-1}$ on next day of Diwali shows the warming state of the lower and middle atmosphere.

Keywords. Black carbon (BC); suspended particulate matter (SPM); aerosol radiative forcing (ARF).

\section{Introduction}

Aerosols interact with solar radiation through scattering and absorption processes thus affecting the radiation balance of the atmosphere (Solomon et al. 2007). Hence, aerosols are one of the crucial constituents of Earth's atmosphere affecting local and regional climatology through direct and indirect atmospheric processes. In addition, the effect of aerosols on air quality and public health remained a central topic in current environmental studies. Several epidemiological studies revealed correlation between high concentration of particulate matter $(\mathrm{PM})$ and severe health hazards that include enhanced mortality, cardiovascular, respiratory and allergic diseases (Bernstein et al. 2004; Pope et al. 2004). The annual report of the World Health Organization (WHO) states that an increase in $10 \mu \mathrm{g} \mathrm{m}^{-3}$ of total $\mathrm{PM}$ gives $6 \%$ more mortality cases with severe respiratory and coughing problems (WHO 2003). In India, during Diwali festival, very high quantity of anthropogenic aerosols is injected into the atmosphere due to burning of crackers and fireworks. Several researchers studied the effect of firework activities on short-term perturbations in an air pollutant level and their chemical composition (Ravindra et al. 2003; Barman et al. 2008; Thakur et al. 2010). 
Their main findings revealed that on such occasions, several air pollutants such as various trace toxic metals of different sizes in the form of suspended particulate matter (SPM), toxic gases and chemical matters are released into the atmosphere above the prescribed limits of their national ambient air quality standards level. Different studies conducted throughout the globe have shown that a rise in $\mathrm{PM}_{10}$ concentration increases the problems related to lung function of children (Moreno et al. 2007). The toxicological studies of airborne particulates have shown that long-term exposure to airborne particulates give promotion to cardiopulmonary, lung cancer mortality and coronary heart diseases (Rosenlund et al. 2008; Heinrich et al. 2013). In addition to this, Rastogi et al. (2019) observed an impact of firecracker on the chemical composition of ambient aerosol over Ahmedabad and contribution of organic aerosols was reported to be maximum $(85 \%)$ to a particle size $<1 \mu \mathrm{m}$. Several studies conducted throughout India during the Diwali period reported an increase in the concentration of black carbon (BC) (Babu and Moorthy 2001 and references therein). BC aerosol is recognised as an important constituent of atmospheric aerosols and considered as an active climate forcing agent. Hence, the aerosols emitted due to burning of crackers and fireworks not only impact the human health but also affect the atmospheric radiative forcing and regional climate. Each year, Diwali festival happens to be either in the month of October or November. From various studies incorporated by Sharma et al. (2011), Singh et al. (2016), etc., over the study site have shown that during this period, additional anthropogenic aerosol emission over the western region of Indo Gangetic Plain (IGP) is due to paddy residue burning in the open fields by the farmers. Several studies carried out during these months in IGP also revealed that high concentration of absorbing aerosol (BC) is injected into the atmosphere (Dey et al. 2006; Surendran et al. 2013; Tiwari et al. 2015; Singh et al. 2016). The absorbing aerosols released during this period have a great impact on aerosol radiative forcing (ARF). The magnitude and sign of aerosol radiative forcing depends on the relative concentration of absorbing and scattering aerosols in a mixture. Absorbing type of aerosols significantly alters the magnitude and sign of the ARF by reducing the aerosols single scattering albedo (SSA). A short-term study reported by Singh et al. (2014) showed an additional atmospheric heating rate of $0.23 \mathrm{~K} \mathrm{day}^{-1}$ during fireworks on Diwali event over Varanasi in India. Firecrackers burning on different occasions all over the globe can profoundly affect ambient air quality, climate and aquatic environment as well.

The present first ever study conducted over Patiala, Punjab focuses on to see the impact of Diwali festival of 19 October 2017 on atmospheric aerosol properties in the presence of highly polluted background atmosphere caused by emission from paddy residue burning during these days over the study region. The main objective of the present study is to investigate the impact of Diwali festival on the physical and optical properties of aerosols with emphasis on radiative forcing which has implications on regional climate. The study period covers 5 days from 17 October to 21 October 2017 to see the variation in aerosol characteristics before and after Diwali days.

\section{Observational details}

\subsection{Site description and local meteorology}

Patiala $\left(30.3^{\circ} \mathrm{N}, 76.4^{\circ} \mathrm{E}, 249 \mathrm{~m}\right.$ above mean sea level) is located in the northwestern part of the IGP, close to Shivalik Hills in the east. The sampling site is located at the roof top of Physics block in Punjabi University campus, semi-urban region on the northeast side of the main Patiala city. Residential quarters of university employees are situated on west and northwest side within $200 \mathrm{~m}$ distance from the observation site while the urban estate of Patiala city is just at $1 \mathrm{~km}$ on the southwest side. There is no major industry around Patiala city and villages having agriculture fields are situated few kilometres away from the site (figure 1a and b). The region is also engulfed by smoke due to paddy residue burning by farmers in the open fields during October and November (Singh et al. 2016). During the study period, weather was mainly dry with temperature varying from minimum $\sim 18^{\circ} \mathrm{C}$ to maximum $\sim 34^{\circ} \mathrm{C}$ and relative humidity (RH) ranging from $40 \%$ to $80 \%$ and wind direction remain northwesterly with an average speed of $\sim 1.2 \mathrm{~km} \mathrm{~h}^{-1}$ as shown in figure $1(\mathrm{c})$.

\subsection{Ground-based measurements}

\subsubsection{Aerosol optical depth (AOD)}

AOD measurements are performed using a handheld multichannel MICROTOPS II (MT) Sun 

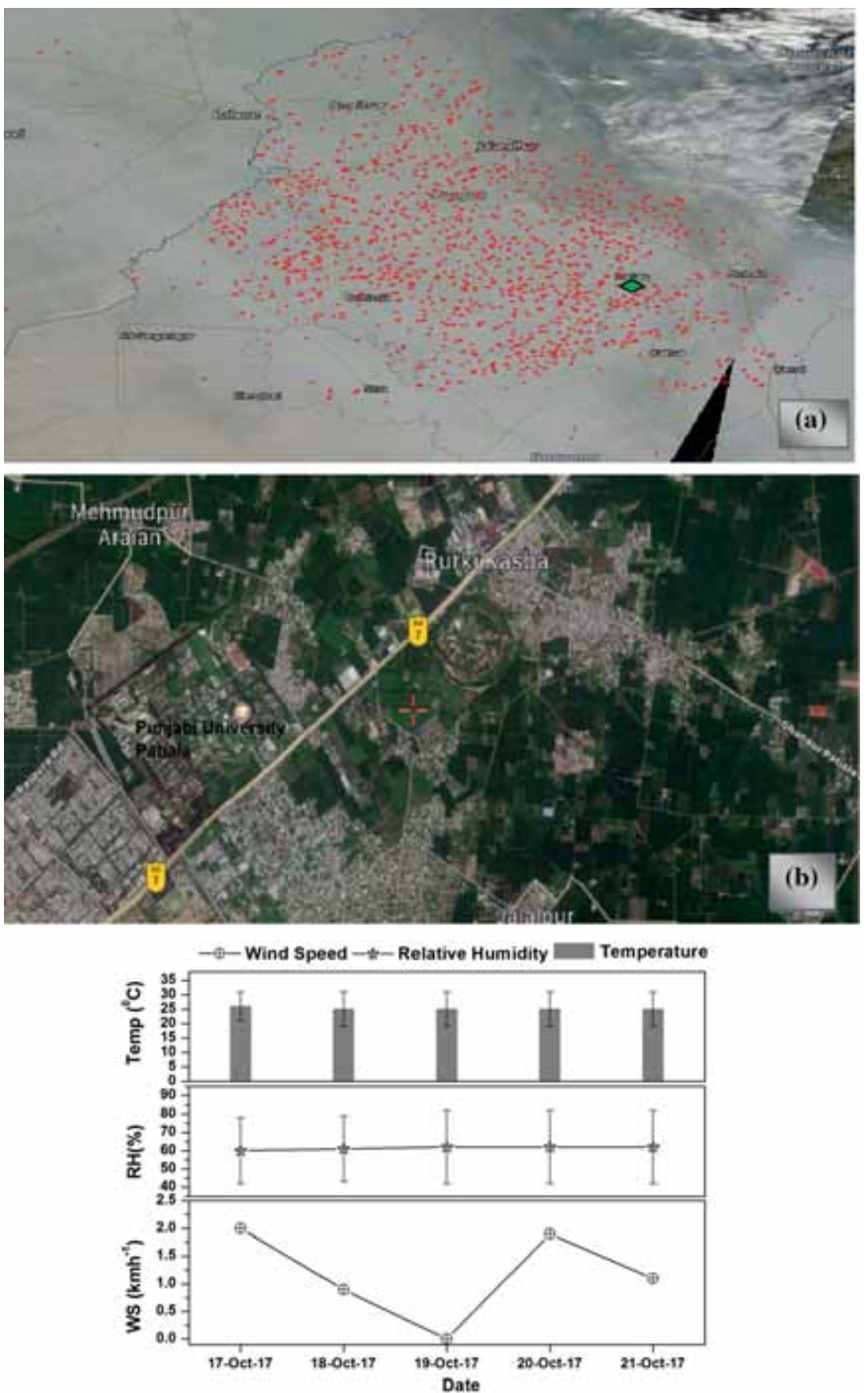

(c)

Figure 1. (a) Geographical location of the sampling site (Patiala: $30.2^{\circ} \mathrm{N}, 76.2^{\circ} \mathrm{E}$ ) in the Indo-Gangetic Plain from MODIS, (b) location of the study site including nearby cities and highway and $(\mathbf{c})$ daily averaged values of temperature $\left({ }^{\circ} \mathrm{C}\right), \mathrm{RH}$ and wind speed $\left(\mathrm{km} \mathrm{h}^{-1}\right)$ with an error bar representing the standard deviation.

photometer of Solar Light Company, USA. This instrument simultaneously measures AOD at five wavelengths, viz., 380, 440, 500, 675 and $870 \mathrm{~nm}$. The full-width at half maximum bandwidth for a $380 \mathrm{~nm}$ channel is $2.4 \pm 0.4 \mathrm{~nm}$ and $10 \pm 1.5$ for other channels. The field of view of Sun photometer is $2.5^{\circ}$. The MT has build in pressure and temperature sensors with GPS connectivity to obtain position and time coordinates. As per its working technique, it measures the intensity of incoming solar radiation at particular wavelengths and then, converting measured intensity into optical depth using its internal calibration and Langley method. The cumulative error of Sun photometers in AOD measurements is found to be $2-5 \%$ for all wavelengths. The combined effects of all sources of 
uncertainty result in total uncertainty in computed spectral AODs of $\sim 0.01-0.025$, which is spectrally dependent with a higher error in the UV region (Morys et al. 2001; Porter et al. 2001).

\subsubsection{BC measurements}

A seven channel Aethalometer (model AE-31, Maggie scientific USA) is used to measure BC mass concentration. It is based on the principle of measuring the attenuation of a beam of light transmitted through a filter, while the filter tape is continuously collecting the aerosol sample. The Aethalometer collects the sample on a quartz fibre filter tape when air passes through it at a constant flow rate of $3.21 \mathrm{~min}^{-1}$ with a measuring interval of $5 \mathrm{~min}$. It monitors optical attenuation of light at wavelengths of $370,470,520,590$, 660,880 and $950 \mathrm{~nm}$. The BC mass concentration is estimated from the change in optical attenuation at $880 \mathrm{~nm}$ as BC is a principal absorber at this wavelength (Hansen 1996). The Aethalometer software uses a constant attenuation cross section $(\sigma$ ATN) of $16.6 \mathrm{~m}^{2} \mathrm{~g}^{-1}$, in determining the $\mathrm{BC}$ mass concentration. The attenuation coefficient $\left(b_{\text {atn }} \mu \mathrm{m}^{-1}\right)$ of $\mathrm{BC}$ from Aethalometer (at $880 \mathrm{~nm}$ ) can be represented mathematically by the following equation:

$$
b_{\text {atn }}=\mathrm{BC}\left(\mu \mathrm{g} \mathrm{m}^{-3}\right) \times 16.6 \mathrm{~m}^{2} \mathrm{~g}^{-1} .
$$

The spectral absorption coefficient of $\mathrm{BC}\left(\mu \mathrm{m}^{-1}\right)$ is calculated by the following equation:

$$
b_{\mathrm{abs}}=\frac{b_{\mathrm{atn}}}{C R(\mathrm{ATN})},
$$

where $C$ and $R$ (ATN) are the two-empirical constants to correct the measured absorption signal for multiple scattering and shadowing effects, respectively. The values of $R=1$ and $C=2.355$, $2.656,2.677,2.733,2.827,2.933$ and 2.925 have been used for seven wavelengths 370, 470, 520, 590, 660, 880 and $950 \mathrm{~nm}$ (Weingartner et al. 2003; Schmid et al. 2006; Sinha et al. 2013). More details of the analytical technique for Aethalometer-based measurements can be found in the literature (Hansen et al. 1984; Hansen 1996).

\subsubsection{Suspended particulate matter}

In the present study, measurement of SPM was performed with the help of a high-volume sampler of Envirotech Company placed at the roof top of Physics Department, at a height of $10 \mathrm{~m}$ above the surface. It separates the fine and coarse mode particles, i.e., respirable particulate matter $\left(\mathrm{RSPM}<\mathrm{PM}_{10}\right)$ and non-respirable particulate matter $\left(\mathrm{NRSPM}>\mathrm{PM}_{10}\right)$ at a flow rate of 1.03 $\mathrm{m}^{3} \mathrm{~min}^{-1}$. When ambient air enters the system through the inlet pipe and the air passes through the cyclone, coarse dust is separated from air stream by centrifugal force acting on solid particles. These particles fall through the cyclone's conical hopper and collected in the sampling cup at the bottom. The fine dust forming the respirable fraction of the total suspended particulate (TSP) is carried by the air stream to the filter paper. Then the RSPM and NRSPM mass concentrations are calculated by a gravimetric method. During the present study sampling was carried out from 9.00 to $17.00 \mathrm{~h}$ during daytime for 5 days.

\subsection{Satellite observations}

\subsubsection{Ozone monitoring instrument}

Aerosol index (AI) values are taken from the Ozone Monitoring Instrument (OMI). OMI is a FinnishDutch ozone monitoring instrument that has been put on NASA Aura mission, a part of Earth Observation System (EOS) and was launched in July 2004. OMI is a nadir-viewing wide-field imaging spectrometer which measures reflected and backscattered solar light in the UV-visible domain (270-500 nm) on daily basis. This instrument was primarily designed for trace gas retrieval, but it contains valuable information on aerosols as well. OMAERUV and OMAERO are two-separate algorithms which have been used for aerosol retrievals from OMI. The OMAERUV algorithm uses only a small range of wavelengths in the near UV from the OMI spectrum; however, the OMAERO algorithm uses the wavelength range from 330 to $500 \mathrm{~nm}$ (Torres et al. 2007). In the present study we have used Aura OMI derived Aerosol Data Product-OMAERO (V003) products obtained from the Giovanni site (http://disc.sci. gsfc.nasa.gov/Giovanni).

\subsection{Model simulations}

\subsubsection{Optical properties}

The software package optical properties of aerosols and clouds (OPAC) is used to estimate the optical properties of aerosols (Hess et al. 1998). This model is widely adopted as it describes a wide range of 
possible aerosol composition in the absence of chemical measurements. In the present study optical parameters such as SSA, asymmetry parameter $(g)$ and phase function $(P(\theta))$ were computed using OPAC as a function of wavelength ranging from 0.25 to $4.0 \mu \mathrm{m}$. Depending on the prevailing atmospheric conditions over the study area, the OPAC model incorporates a mixture of five aerosols which are insoluble, water-soluble, BC (soot), mineral (accumulation mode) and mineral transported. In the present study, BC mass concentration measured with an Aethalometer was obtained with an overall uncertainty of $\sim 20 \%$ (Moorthy et al. 2007) and a high-volume sampler was used for measurements of the mass concentration of composite aerosols with an average uncertainty of $\sim 5 \%$. By fixing the $\mathrm{BC}$ mass mixing ratio (ratio of the mass concentration of $\mathrm{BC}$ to the total mass of the composite aerosols), number densities of other aerosol components are varied. A number of iterations are performed so that the estimated AOD and Angstrom wavelength exponent are in good agreement with the observed values (Babu et al. 2002) and the root mean square difference between model derived and measured spectral AOD is 0.02 in the present study. This model permits the use of eight values of $\mathrm{RH}(0 \%$, $50 \%, 70 \%, 80 \%, 90 \%, 95 \%, 98 \%$ and $99 \%)$ which play an important role in the reconstruction of AOD. We used the value closest to the mean $\mathrm{RH}$ during the study period.

\subsubsection{Aerosol radiative forcing}

A change in radiation flux due to the presence of atmospheric aerosols is referred to as aerosol radiative forcing. The effect of aerosols on radiative flux at top of the atmosphere (TOA) and at the surface is known as TOA radiative forcing and surface radiative forcing, respectively. The atmospheric radiative forcing (ATM) is the difference between radiative forcing at top of atmosphere (TOA) and radiative forcing at surface (SRF). In all cases (i.e., surface, atmosphere and TOA) aerosol forcing is the difference in radiative fluxes with and without aerosols. This can be estimated by a SBDART (Santa Barbara DISORT Atmospheric Radiative Transfer) code developed by University of California, Santa Barbara (Ricchiazzi et al. 1998). It computes parallel plane radiative transfer in clear and cloudy conditions within Earth's atmosphere and

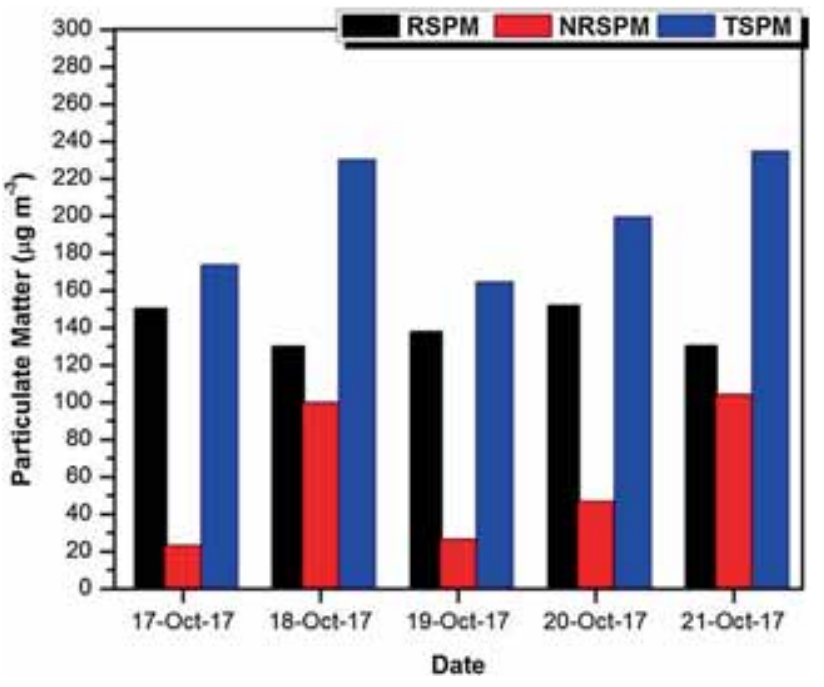

Figure 2. Variability in PM during the study period.

at the surface. The observed values of AOD and angstrom exponent $(\alpha)$ and estimated values of SSA and asymmetry parameter $(g)$ using the OPAC software package are used as an input to SBDART to compute aerosol radiative forcing at the surface and TOA on daily basis. In the present study, the surface albedo was obtained using a MODIS Albedo product (MODIS/Terra + Aqua albedo 16-day L3 global $1 \mathrm{~km}$ SIN Grid V005), which provides both white-sky albedo as well as black-sky albedo for MODIS spectra of 0.645-2.13 $\mu \mathrm{m}$ (https://wist.echo.nasa.gov/api). Based on the prevailing meteorological conditions over Patiala, a mid-latitude winter atmospheric profile was adopted for the study period while estimating ARF using the SBDART model. Knowing the daily value of ATM, the aerosolgenerated atmospheric heating can be estimated by following Liou (2002) as:

$$
\frac{\partial T}{\partial t}=\frac{g}{C_{p}} \frac{\Delta F}{\Delta P}
$$

where $\partial T / \partial t$ is the heating rate $\left(\mathrm{K} \mathrm{day}^{-1}\right), g$ is the acceleration due to gravity, $C_{p}$ is the specific heat capacity of air at constant pressure $(\sim 1006 \mathrm{~J}$ $\left.\mathrm{kg}^{-1} \mathrm{~K}^{-1}\right), \Delta F$ is the resultant atmospheric forcing and $\Delta P$ is the atmospheric pressure difference $(\sim 300 \mathrm{hPa})$ between the top and bottom boundaries of each layer. A major amount of aerosols are present in the lower level and contribute to atmospheric heating; hence, pressure difference is taken as $300 \mathrm{hPa}$ (Quijano et al. 2000a, b; Lubin et al. 2002). 


\section{Results and discussion}

\subsection{Variation in PM}

The results of the measurements of SPM with HVS were recorded from 17 to 21 October 2017 and are shown in figure 2 . The averaged mass concentration of RSPM was around $\sim 140 \pm 10 \mu \mathrm{g} \mathrm{m}^{-3}$ during the whole study period with a maximum concentration of $\sim 155 \mu \mathrm{g} \mathrm{m}^{-3}$ on post-Diwali day which is attributed to remnants of additional fine particle loading into the atmosphere due to intense burning of crackers and fireworks on Diwali night. The RSPM concentration decreases thereafter when the additional load of fine particles subsides. On the other hand, the NRSPM concentration ranged from 23 to $100 \mu \mathrm{g} \mathrm{m}^{-3}$ but showing no systematic variations during the study period which may partly be attributed to a change in combine harvesting activity of paddy crop in the nearby fields along with other anthropogenic activities contributing to coarse mode particles. In India, Diwali celebrations are performed with such an enthusiasm that farmers do not work in fields and hence there is no combine harvesting of paddy resulting in a low value of NRSPM on this day. The mass concentration of TSPM varied from 164 to $234 \mu \mathrm{g} \mathrm{m}{ }^{3}$ throughout the study period. Earlier studies show that the mass concentration of $\mathrm{PM}_{10}$ increases by 2-6 times during Diwali in various cities of India (Verma and Dhananjay 2014). In the present study, the mass concentration of $\mathrm{PM}_{10}$
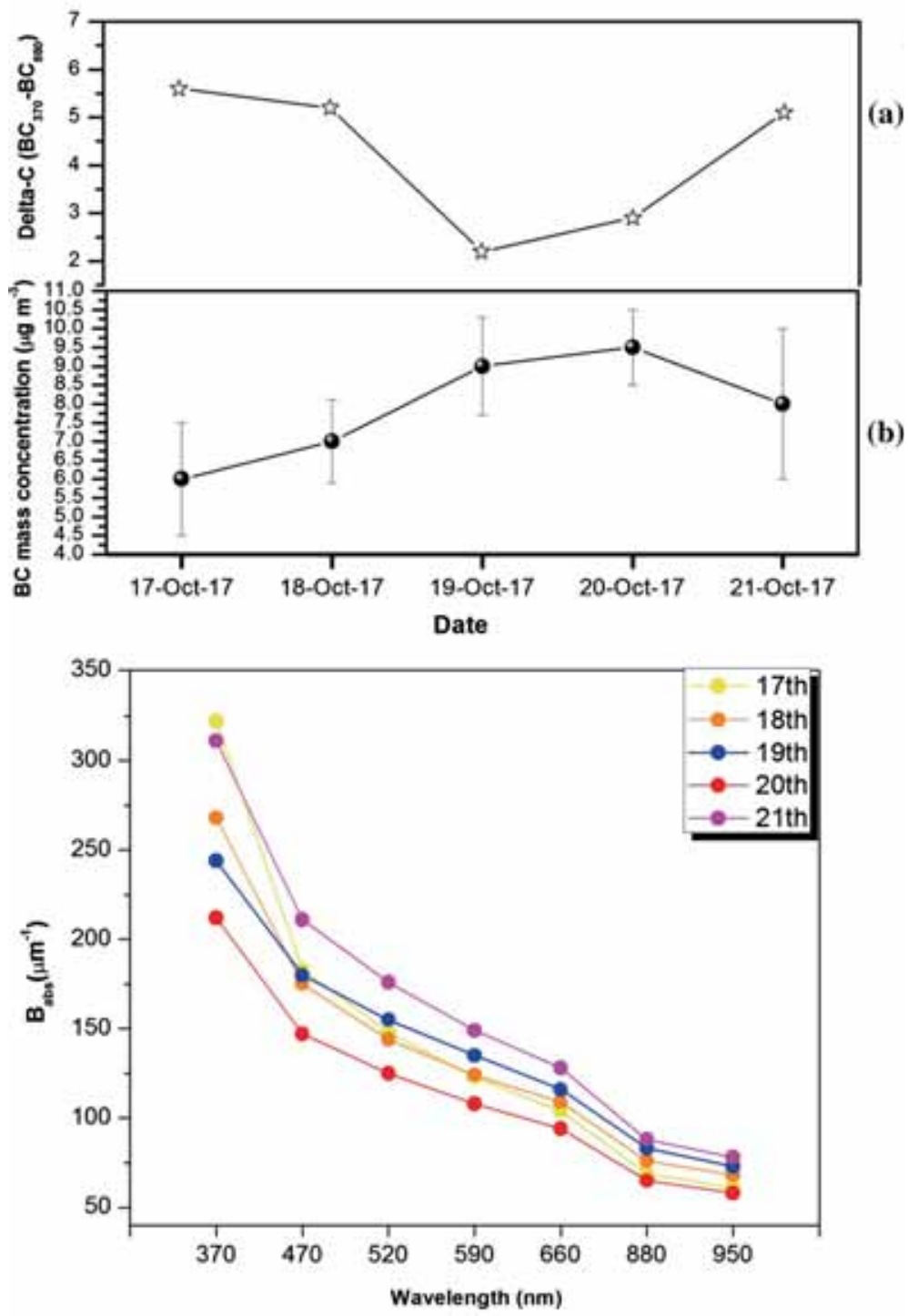

(c)

Figure 3. (a) Delta- $C$ values for source apportionment during Diwali period, (b) daily variation in BC mass concentration, and (c) spectral dependence of absorption coefficient $\left(b_{\mathrm{abs}}\right)$. 
on the next day of Diwali day is $\sim 3$ times higher than the national ambient air quality standards $\left(\mathrm{PM}_{10}=60\right.$ and $\left.\mathrm{PM}_{2.5}=40 \mu \mathrm{g} \mathrm{m}^{-3}\right)$. This increment in $\mathrm{PM}_{10}$ fraction during and post-Diwali festival may have a significant impact on human health and results in poor air quality over the region.

\subsection{Variation in $B C$ mass concentration with source apportionment}

The mass concentration of $\mathrm{BC}$ was monitored during the study period to quantify the impact of Diwali festival on its abundance. Daily averaged variation in a mass concentration of $\mathrm{BC}$ during daytime shown in figure $3(\mathrm{~b})$ revealed that the $\mathrm{BC}$ mass concentration remains high for Diwali affected days. The maximum concentration of about $\sim 9 \pm 1 \mu \mathrm{g} \mathrm{m}^{-3}$ was observed on 19 th and 20 th October and mass fraction varied from $3 \%$ to $5 \%$ during the study period. Almost similar variations are observed in a concentration of $\mathrm{PM}_{10}$ during these days as discussed above. During the observation period, the study region also experiences paddy residue burning (Singh et al. 2016) which enhances the concentration of BC aerosol into the atmosphere in addition to emission due to celebration of Diwali festival.

In order to estimate the contribution of biomass burning vis-à-vis due to fossil fuel burning as sources of BC aerosols during the present study, we have calculated Delta- $C\left(\mathrm{BC}_{370}-\mathrm{BC}_{880}\right)$. High values of Delta- $C$ indicate dominant contribution from biomass burning whereas low values attribute to dominance of fossil fuel combustion (Wang et al. 2011). The plot of Delta- $C$ for the present study shows that the Delta- $C$ value is high $\sim 5.6$ on 17 th October and decreases to the lowest value of $\sim 2.2$ on Diwali day and attains almost the initial value after 2 days of Diwali (figure 3a). A power law relation is used to estimate the wavelength $(\lambda)$ dependence of absorption coefficient $\left(b_{\mathrm{abs}}\right)$ :

$$
b_{\mathrm{abs}} \propto \lambda^{-\alpha} .
$$

Figure 3(c) shows the spectral variation of absorption coefficients for each day, where $\alpha$ is usually called the Angstrom exponent computed by employing exponential curve fitting to a plot of Aethalometer-based $b_{\text {abs }}$ as a function of wavelength (370-950 nm). It shows high values for 17th, 18th and 21st October and low values for 19th and 20th October. Similarly, the Angstrom absorption exponent (AAE) varies from 1.25 to 1.63 during the study period. Low values of AAE (1.25 and 1.33 ) on 19th and 20th October indicate dominant contribution from fossil fuel emission. This clearly indicates that during Diwali festival, fossil fuel burning is the dominant source of BC as compared to biomass burning and its effect subsides during subsequent days to Diwali.

\subsection{Variations in optical and radiative properties}

Spectral AOD measurements were made using a Microtops II sun photometer on hourly basis during daytime and averaging of hourly values provide one data set of spectral AOD for the whole day. Day-to-day variation of spectral AOD during the study period is shown in figure 4 . It is evident from the figure that AOD at lower wavelengths is more affected than at the longer wavelengths. During pre-Diwali days, AOD values at $500 \mathrm{~nm}$ decrease gradually from 0.622 to a minimum value of 0.556 on Diwali day but suddenly jumps to 0.852 on next day of Diwali (table 1). This significant increase of

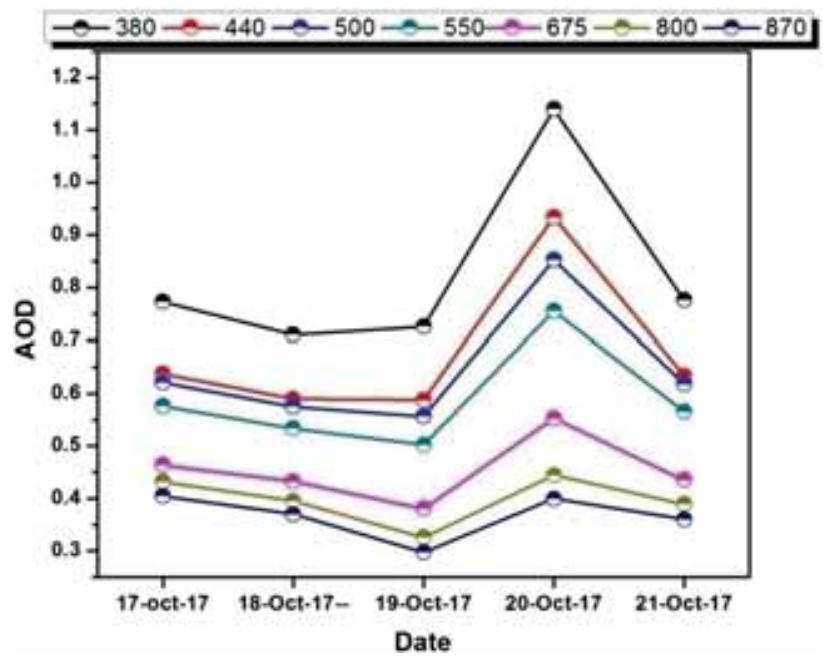

Figure 4. The spectral variation of the AOD during the study period.

Table 1. Daily values of $A O D_{500}, A I$ and Angstrom exponent $(\alpha)$.

\begin{tabular}{lccc}
\hline Date & $\begin{array}{c}\text { AOD at } \\
500 \mathrm{~nm}\end{array}$ & OMI AI & $\begin{array}{c}\text { Angstrom } \\
\text { exponent }(\alpha)\end{array}$ \\
\hline 17-Oct-2017 & 0.621 & 0.96 & 0.8 \\
$18-$ Oct-2017 & 0.575 & 0.97 & 0.9 \\
19-Oct-2017 & 0.556 & 0.99 & 1.1 \\
$20-$ Oct-2017 & 0.852 & 1.04 & 1.3 \\
$21-$ Oct-2017 & 0.618 & 1.05 & 1.0 \\
\hline
\end{tabular}




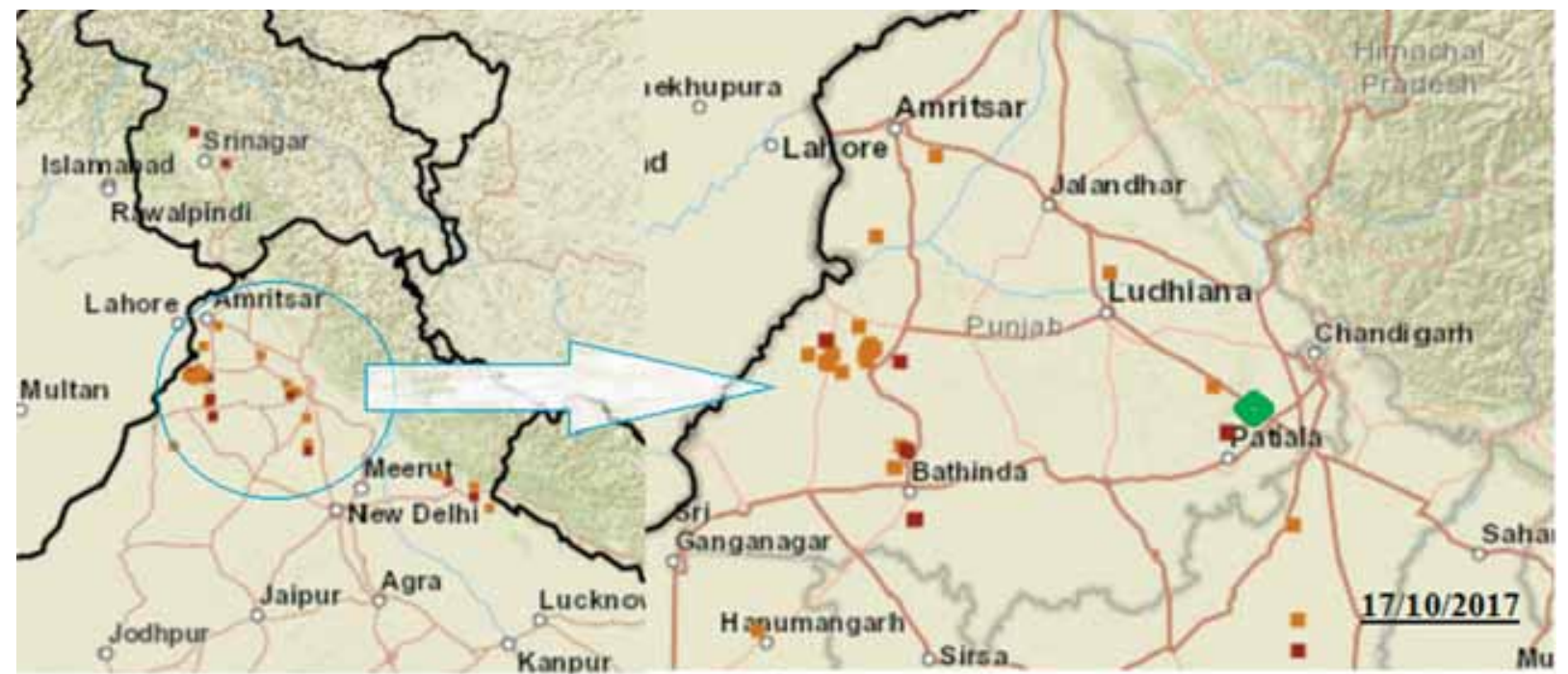

(a)

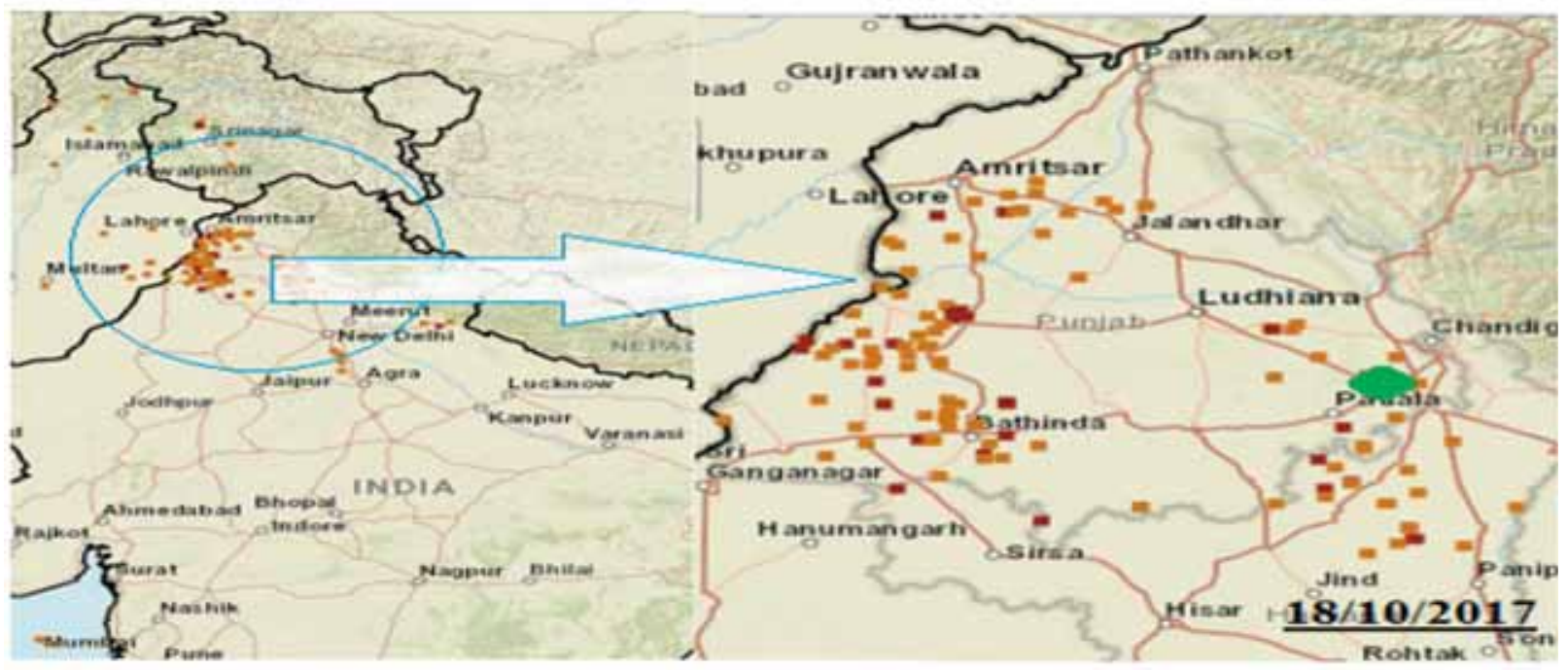

(b)

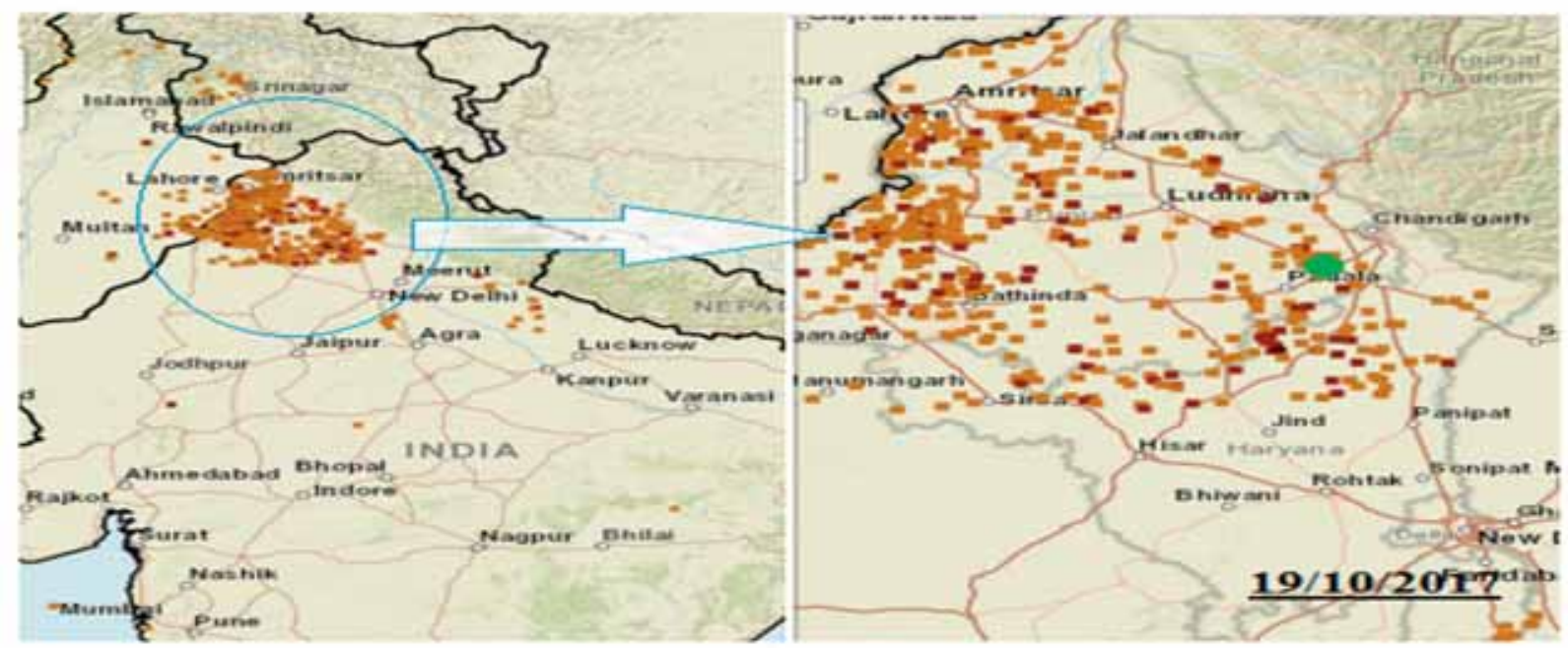

(c)

Figure 5. (a-e) Images of VIIRS satellite images of fire counts during the study period. 


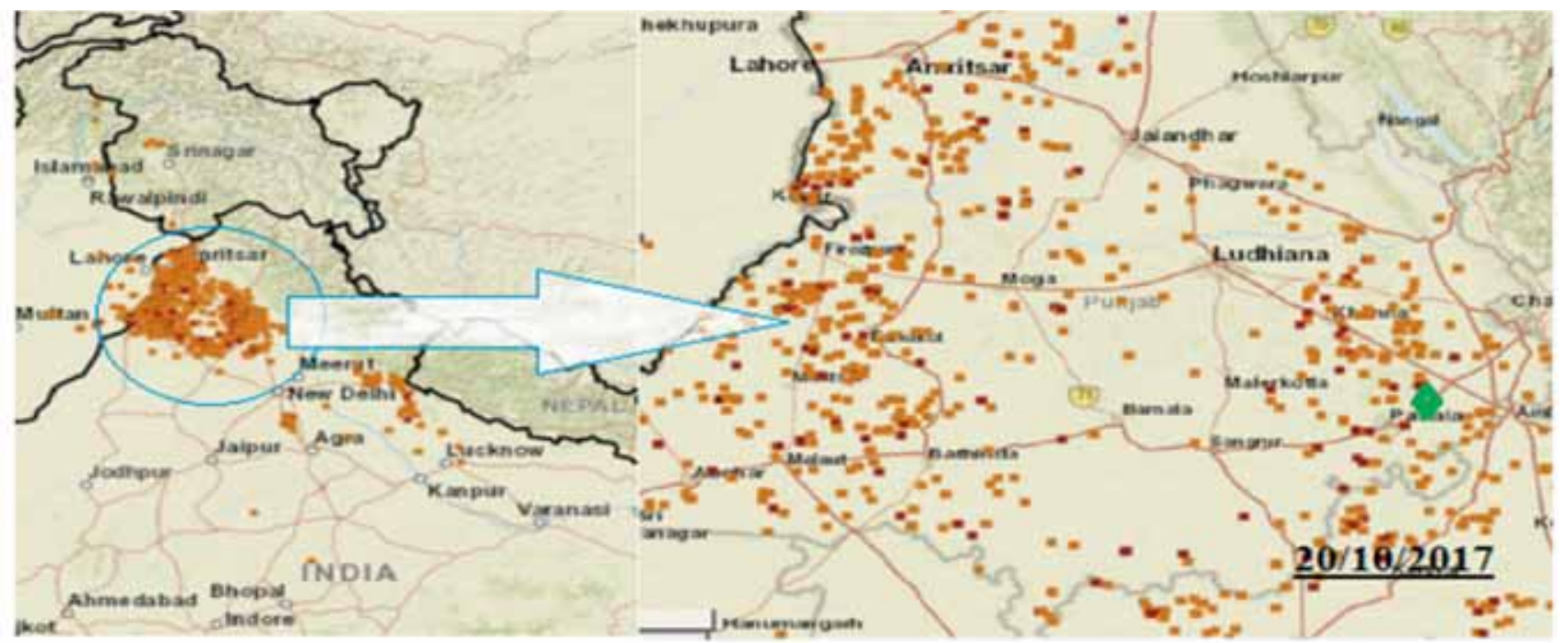

(d)

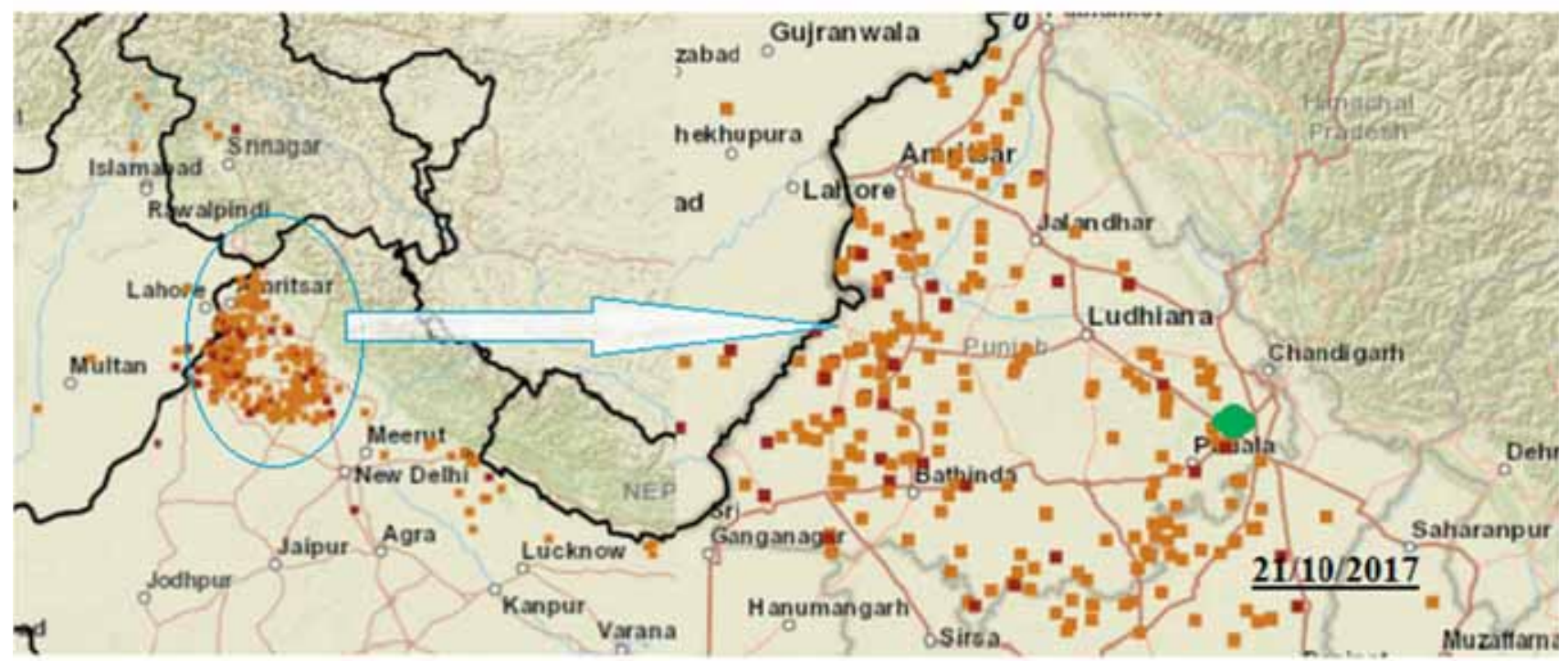

(e)

Figure 5. (Continued.)

AOD on next day (20th October) of Diwali is attributed to additional loading of aerosols due to burning of crackers and fireworks on the night of this festival. Earlier studies by Babu and Moorthy (2001) at Thumba during Diwali festival observed enhanced AODs which were attributed to an enhanced concentration of black and organic carbon, generated by burning of different types of crackers and fireworks while Singh et al. (2003, 2014) reported an enhancement of $\sim 5.7 \%$ and $\sim 27 \%$ in values of $\mathrm{AOD}_{500}$ at Kanpur and Varanasi, respectively.

In addition, Angstrom exponent $(\alpha)$ values estimated from the spectral AOD values using the least squares method over the range of $380-870 \mathrm{~nm}$ remained high $\sim 1$ for all days (table 1 ). During the study period, paddy residue burning also takes place around the sampling site, thus there is a combined effect of emission from both biomass and crackers burning on high values of $\alpha$ around Diwali days. However, the highest value of the Angstrom exponent on 20th October indicates the abundance of sub-micron size particles due to the impact of Diwali celebrations on previous night. In order to observe the fire activity over the larger region around the study site, Visible Infrared Imaging Radiometer Suite (VIIRS)-derived images of 5 days from 17th to 21st October all over the Punjab region, India are shown in figure $5(\mathrm{a}-\mathrm{e})$. Though large number of fire counts can be seen clearly over 


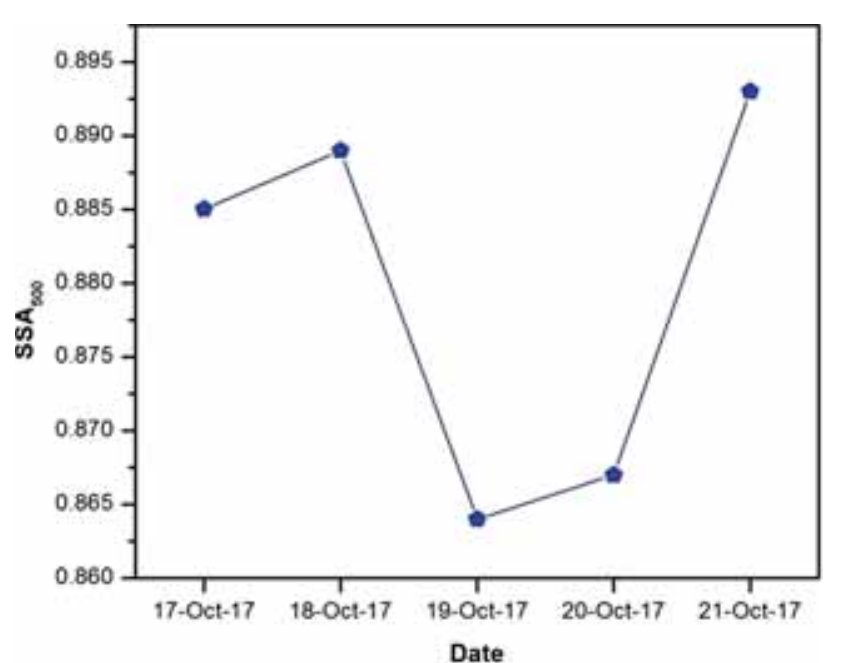

(a)

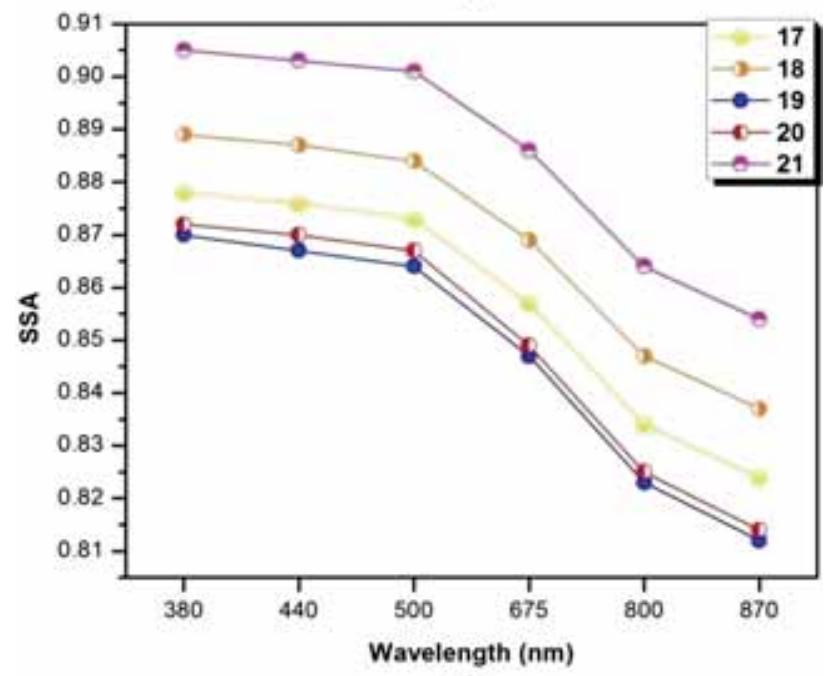

(b)

Figure 6. (a) Daily variation of OPAC-derived $\mathrm{SSA}_{500}$ values and (b) spectral dependence of SSA during the study period.

Punjab during the study period but more intensely on 19th and 20th of October because of Diwali event as described earlier.

SSA is a key input parameter for the calculation of radiative forcing which represents relative contribution of absorption and scattering to the total extinction of solar radiation by aerosols. The magnitude of SSA ranges between zero for purely absorbing and one for purely scattering type of aerosols (Satheesh et al. 2010). In the present study, spectral SSA was estimated over the study region by using the OPAC model (Hess et al. 1998). $\mathrm{SSA}_{500}$ values decrease from 0.885 on 17 th October to a minimum value of 0.864 on Diwali day and a slight increase next day to Diwali but again jumps to 0.893 on 21 st October (figure $6 \mathrm{a}$ ). Moreover, the lowest values of SSA $(\sim 0.864)$ on Diwali and next day $(\sim 0.867)$ clearly indicate additional release of absorbing aerosols due to fireworks and crackers as compared to other days during the present study. SSA values are slightly low on 19th compared to 20th October due to a small increase in BC mass fraction on 19th (0.05) as compared to 20th (0.04). An increase in the BC mass fraction on 19th October may be attributed to no wind condition (calm atmosphere, figure 1c) which results in negligible dispersion of pollutants resulting in the accumulation of $\mathrm{BC}$ in the lowest atmosphere. On the other hand, on 20th October prevailing lowwind conditions result in dispersion of surfacebased BC to some extent that may result in slightly lower BC mass fraction than on 19th October. In Varanasi also, $\mathrm{SSA}_{500}$ values decrease from 0.954 to 0.950 during Diwali affected days (Singh et al. 2014). SSA is also wavelength dependent and it decreases with an increase of wavelength showing abundance of fine mode particles particularly BC over the coarse mode into the atmosphere during the study period (figure 6b) (Dey et al. 2004; Tiwari et al. 2013). In addition to this, AI is another important parameter derived from OMI satellite which is highly useful for the detection of absorbing aerosols, like BC desert dust in the atmosphere (Torres et al. 1998; Kaskaoutis et al. 2010). From table 1, positive and high values of AI during the study period indicate a significant amount of UV absorbing aerosols. Higher values of the AI on Diwali and next day than other days again indicate abundance of UV absorbing aerosols on these 2 days. ARF which involves scattering and absorption of incoming solar radiation by aerosols present in the atmosphere at any location depends on the nature of aerosols and their distribution, SSA, underlying surface albedo and RH, etc. (Haywood and Boucher 2000). The radiative forcing from anthropogenic aerosols has been a subject of scientific research throughout the globe. $\mathrm{ARF}$ calculations were performed in the shortwave range of $0.25-4.0 \mu \mathrm{m}$ separately at surface (SRF), TOA and within the atmosphere (ATM) by using the SBDART model. Figure 7 shows short-wave direct SRF, TOA and ATM over the sampling site. A significant increase in SRF (approx. $-13 \mathrm{~W} \mathrm{~m}^{-2}$ ) was observed on post-Diwali day. Similarly TOA radiative forcing was minimum on Diwali and next day thus resulting in the maximum atmospheric shortwave forcing (ATM) of about $+44 \mathrm{~W} \mathrm{~m}^{-2}$ with a heating rate of up to $1.4 \mathrm{~K} \mathrm{day}^{-1}$ on next day of Diwali. This is due to the fact that most of the fireworks and burning of crackers take place on the night of Diwali day and 


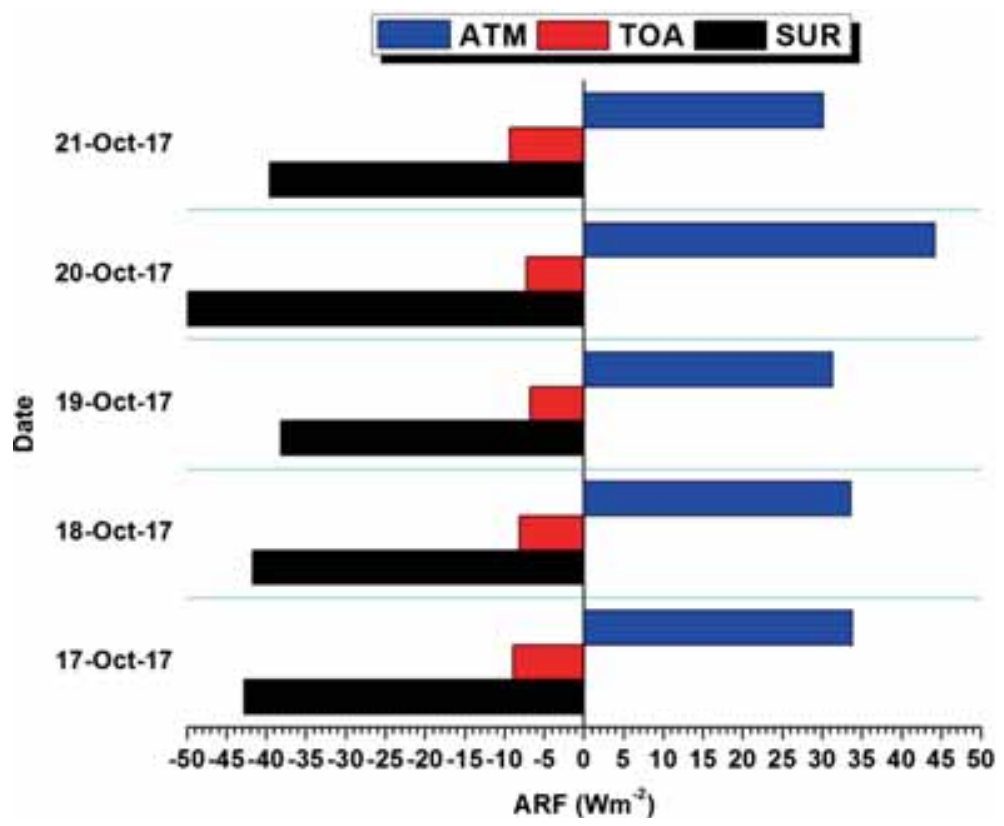

Figure 7. Variation of aerosol radiative forcing values at SRF, TOA and ATM during the study period.

its effect is apparent from high-ATM radiative forcing and the heating rate on the next day of Diwali. In a similar study, Singh et al. (2014) have estimated approx. $+12 \mathrm{~W} \mathrm{~m}^{-2}$ increment in atmospheric radiative forcing during the Diwali affected period compared to other days over Varanasi. Thus our results of ARF calculations show a significant impact of Diwali celebrations on the atmospheric radiative forcing which can result in warming of the lower and middle atmosphere. Thus aerosol emission due to an episodic event arising due to Diwali celebrations can affect the lower atmospheric dynamics and has the potential of changing the regional climate.

\section{Conclusions}

The present study examined the effect of Diwali festival on the physical, optical and radiative properties of aerosols over Patiala, in the northwest part of India. The major conclusions drawn from the present study are as follows:

- High-PM $\mathrm{PM}_{10}$ concentration of $\sim 155 \mu \mathrm{g} \mathrm{\textrm {m } ^ { - 3 }}$ during the Diwali event indicates poor air quality over the study region having potential to affect the human health.

- A significant increase in the fraction of $\mathrm{BC}$ aerosols from $3 \%$ to $5 \%$ is attributed to emission from burning of crackers and fireworks during Diwali festival.
- Approximately $40 \%$ increase in AOD values on next day of Diwali festival in comparison with pre-Diwali day indicates the extra loading of aerosols released during Diwali night.

- The high value of the Angstrom coefficient $\alpha$ ranging between 1.1 and 1.3 during Diwali days is attributed to the abundance of sub-micron particles released into the atmosphere.

- The lowest SSA values of $\sim 0.864$ and $\sim 0.867$ on and after Diwali day are attributed to additional $\mathrm{BC}$ emission from firework activities.

- A significant increase in atmospheric aerosol radiative forcing of $+44 \mathrm{~W} \mathrm{~m}^{-2}$ observed due to Diwali celebrations over Patiala can result in warming of the lower atmosphere up to $1.4 \mathrm{~K} \mathrm{day}^{-1}$ having potential of affecting the atmospheric dynamics and the regional climate.

\section{Acknowledgements}

The work was supported under ISRO-GBP research project and authors are grateful to ISRO for financial support. They also thank to Giovaani, MODIS NASA, and OMI teams for providing the data.

\section{References}

Babu S S and Moorthy K K 2001 Anthropogenic impact on aerosol black carbon mass concentration at a tropical coastal station: A case study; Curr. Sci. 81 1208-1214. 
Babu S S, Satheesh S K and Moorthy K K 2002 Aerosol radiative forcing due to enhanced black carbon at an urban site in India; Geophys. Res. Lett. 29 271-274.

Barman S C, Singh R, Negi M P S and Bhargava S K 2008 Ambient air quality of Lucknow city (India) during use of fireworks on Diwali festival; Environ. Monit. Assess. 137 495-504.

Bernstein J A, Alexis N, Barnes C, Bernstein I L, Nel A, Peden D, Diaz-Sanchez D, Tarlo S M and Williams P B 2004 Health effects of air pollution; J. Allergy Clin. Immunol. 114 1116-1123.

Dey S, Tripathi S N and Singh R P 2004 Influence of dust storms on the aerosol optical properties over the IndoGangetic basin; J. Geophys. Res. 109 D20211, https://doi. org/10.1029/2004jd004924.

Dey S, Tripathi S N, Singha P R and Holben B N 2006 Retrieval of black carbon and specific absorption over Kanpur city, northern India during 2001-2003 using AERONET data; Atmos. Environ. 40 445-456.

Hansen A D A, Rosen H and Novakov T 1984 The Aethalometer an instrument for the real-time measurement of optical absorption by aerosol particles; Sci. Total Environ. 36 191-196.

Hansen A D A 1996 Magee scientific Aethalometer user's guide; Magee Scientific, Berkeley, CA, Vol. 36, pp. 191-196.

Haywood J and Boucher O 2000 Estimates of the direct and indirect radiative forcing due to troposphere aerosols: A review; Rev. Geophys. 38 513-543.

Heinrich J, Thiering E, Rzehak P, Krämer U, Hochadel M, Rauchfuss K M, Gehring U and Wichmann H E 2013 Longterm exposure to $\mathrm{NO}_{2}$ and $\mathrm{PM}_{10}$ and all-cause and causespecific mortality in a prospective cohort of women; Occup. Environ. Med. 70 179-186.

Hess M, Koepke P and Schultz I 1998 Optical properties of aerosols and clouds: The software package OPAC; Bull. Am. Meteorol. Soc. 79 831-844.

Kaskaoutis D G, Nastos P T, Kosmopoulos P G, Kambezidis H D, Kharol S K and Badarinath K V S 2010 The Aura-OMI aerosol index distribution over Greece; Atmos. Res. 98 28-39.

Liou K N 2002 An introduction to atmospheric radiation; Elsevier, New York, 583p.

Lubin D, Satheesh S K, McFarquhar G and Heymsfield A J 2002 Longwave radiative forcing of Indian Ocean tropospheric aerosol; J. Geophys. Res. 107 D19.

Moreno T, Querol X, Alastuey A, Minguillón M C, Pey J and Rodriguez S 2007 Recreational atmospheric pollution episodes: Inhalable metalliferous particles from fireworks displays; Atmos. Environ. 41 913-922.

Moorthy K K, Babu S S, Satheesh S K, Srinivasan J and Dutt C B S 2007 Dust absorption over the 'Great Indian Desert' using ground based and satellite remote sensing; $J$. Geophys. Res. 112 D09206.

Morys M, Mims F M, Hagerup S, Anderson S E, Baker A, Kia J and Walkup T 2001 Design, calibration and performance of Microtops II handheld ozone monitor and Sun photometer; J. Geophys. Res. 106 14573-14582.

Pope C A, Burnett R T, Thurston G D, Thun M J, Calle E E, Krewski D and Godleski J J 2004 Cardiovascular mortality and long term exposure to particulate air pollution: Epidemiological evidence of general pathophysiological pathways of disease; Circulation 109 71-77.
Porter J N, Miller M, Pietras C and Mottel C 2001 Ship based sunphotometer measurements using Microtops Sun photometers; J. Atmos. Ocean. Technol. 18 765-774.

Quijano A L, Sokolik I N and Toon O B 2000a Influence of the aerosol vertical distribution on the retrievals of aerosol optical depth from satellite radiance measurements; $J$. Geophys. Res. Lett. 27 3457-3460.

Quijano A L, Sokolik I N and Toon O B 2000b Radiative heating rates and direct radiative forcing by mineral dust in a cloudy atmospheric conditions; J. Geophys. Res. 105 12,207-12,219.

Rastogi N, Singh A and Satish R 2019 Characteristics of submicron particles coming from a big firecrackers burning event: Implications to atmospheric pollution; Atmos. Pollut. Res. 10 629-634.

Ravindra K, Mor S and Kaushik C P 2003 Short-term variation in air quality associated with fireworks events: A case study; J. Environ. Monit. 5 260-264.

Ricchiazzi P, Yang S, Gautier C and Sowle D 1998 SBDART: A research and teaching software tool for plane parallel radiative transfer in the Earth's atmosphere; Bull. Am. Meteorol. Soc. 79 2101-2114.

Rosenlund M, Picciott S, Forastiere F, Stafoggia M and Perucci C A 2008 Traffic-related air pollution in relation to incidence and prognosis of coronary heart disease; Epidemiology 19 121-128.

Satheesh S K, Vinoj V and Moorthy K K 2010 Radiative effects of aerosols at an urban location in southern India: Observations versus mode; Atmos. Environ. 44 5295-5304.

Schmid O, Artaxo P, Arnott W P, Chand D, Gatti L V, Frank G P, Hoffer A, Schnaiter M and Andreae M O 2006 Spectral light absorption by ambient aerosols influenced by biomass burning in the Amazon basin. I: Comparison and field calibration of absorption measurement techniques; Atmos. Chem. Phys. 6 3443-3462.

Sharma D, Singh M and Singh D 2011 Impact of post-harvest biomass burning on aerosol characteristics and radiative forcing over Patiala, North-West region of India; J. Inst. Eng. 8(3) 11-24.

Singh R P, Dey S and Holben B 2003 Aerosol behaviour in Kanpur during Diwali festival; Curr. Sci. 84 1302-1304.

Singh B P, Srivastava A K, Tiwari S, Singh S, Singh R K, Bisht D S, Lal D M, Singh A K, Mall R K and Srivastava M K 2014 Radiative impact of fireworks at a tropical Indian location: A case study; Adv. Meteorol. 2014, https://doi. org/10.1155/2014/197072.

Singh A, Rastogi N, Patel A, Satish R V and Singh D 2016 Size-segregated characteristics of carbonaceous aerosols over the Northwestern Indo-Gangetic Plain: Year round temporal behavior; Aerosol Air Qual. Res. 16 1615-1624.

Sinha P R, Manchanda R K, Kaskaoutis D G, Kumar Y B and Sreenivasan S 2013 Seasonal variation of surface and vertical profile of aerosol properties over a tropical urban station Hyderabad, India; J. Geophys. Res. Atmos. 118 749-768.

Solomon S, Qin D, Manning M, Chen Z, Marquir M, Averyt K B, Tignor M and Miller H L 2007 Intergovernmental panel on climate change: The physical science basis; Contribution of working group I to the fourth assessment report of the intergovernmental panel on climate change, Cambridge University Press, New York.

Surendran D E, Beig G, Ghude S D, Panicker A S, Manoj M G, Chate D M and Ali K 2013 Radiative forcing of black 
carbon over Delhi; Int. J. Photoenergy, https://doi.org/10. $1155 / 2013 / 313652$.

Thakur B, Chakraborty S, Debsarkar A, Chakrabarty S and Srivastava R C 2010 Air pollution from fireworks during festival of lights (Deepawali) in Howrah, India - A case study; Atmosfera 23 347-365.

Tiwari S, Srivastava A K and Singh A K 2013 Heterogeneity in pre-monsoon aerosol characteristics over the IndoGangetic basin; Atmos. Environ. 77 738-747.

Tiwari S, Dumka U C, Kaskaoutis D G, Panicker A S, Srivastava M K, Tiwari Sh, Attri S D, Soni V K and Pandey A K 2015 Aerosol chemical characterization and role of carbonaceous aerosol on radiative effect over Varanasi in central Indo-Gangetic Plain; Atmos. Environ. 125 1-13, https://doi.org/10.1016/j.atmosenv.2015.07.031.

Torres O, Bhartia P K, Herman J R, Ahmad Z and Gleason J 1998 Derivation of aerosol properties from satellite measurements of backscattered ultraviolet radiation: Theoretical basis; J. Geophys. Res. 103 17,099-17,110.
Torres O, Tanskanen A, Veihelmann B, Ahn C, Braak R, Bhartia P K, Veefkind P and Levelt P 2007 Aerosols and surface UV products from Ozone monitoring instrument observations: An overview; J. Geophys. Res. 112 D24S47, https://doi.org/10.1029/2007jd008809.

Verma C and Dhananjay K D 2014 The ambient air and noise quality in India during Diwali festival: A review; Recent Res. Sci. Technol. 6 203-210.

Wang Y, Hopke Philip K, Rattigan Oliver V and Zhuc Yi 2011 Characterization of ambient black carbon and wood burning particles in two urban areas; J. Environ. Monit. 13 $1919-1926$.

Weingartner E, Saathoff H, Schnaiter M, Strit N, Bitnar B and Baltensperger U 2003 Absorption of light by soot particles: Determination of the absorption coefficient by means of aethalometers; J. Aerosol. Sci. 34 1445-1463.

World Health Organization 2003 Health aspects of air pollution with particulate matter, ozone and nitrogen dioxide report on a WHO working group; Bonn, Germany, pp. 13-15.

Corresponding editor: Suresh BABU 